\title{
ANAESTHETIC TIME/DOSE CURVES. V. DATA ON. NEUROLEPTIC DRUGS WITH REMARKS ABOUT THEIR ACTION*
}

\author{
Michael Kè̀ri-Szàntò, M.D., Francois Telmosse, M.d. $\nmid$ † and Davy Trop, M.D.
}

Previous communications from this department have stated that the construction of anaesthetic time/dose curves provides a practical semi-quantitative tool for comparing the potency of various anaesthetic drugs. ${ }^{1}$ We have shown ${ }^{2}$ that the empirical curves correlate closely with the equation

$$
Y=A t+B\left(1-e^{-k t}\right),
$$

which is in effect the mathematical expression of a statement that during anaesthesia a constant blood-level of the anaesthetic is maintained in the face of initial equilibration and continued transformation of the drug; and that the initial equilibration space can be regarded as a single compartment for the purpose of analysing drug-requirements under clinical conditions. The constant $A$ in the equation represents the apparent rate of transformation; $B$, the amount of drug required to maintain an equilibrium in the apparent distribution space during anaesthesia; $e$ is the base of natural logarithms; $k$, the rate of equilibration; $t$, the anaesthesia time; and $Y$, the subject's cumulative drug requirement. We have used this equation to obtain additional information about the fate of anaesthetics in the body under actual clinical conditions. ${ }^{1}$

Recent reports from Europe ${ }^{3,4}$ claimed that a mixture of two intravenous agents, one a derivative of meperidine, the other butyrophenone, a new generic compound, will produce general anaesthesia that is in some ways qualitatively different from the general anaesthesia we have now, an advance over previous methods. The word "neuroleptic anaesthesia" has been coined to describe this state. When one of us (D.T.) received a sample_of the newest modifications of the two drugs ( $\mathrm{R}-4749$ and R-4263) from the manufacturer (Dr. C. Janssen Research Laboratories, Beerse, Belgium) it appeared of interest to study their action under previously established standard conditions, to compare their potency with known intravenous anaesthetics, and to observe any differences that might appear between the behaviour of patients under the influence of this mixture and that ordinarily expected under general anaesthesia.

\section{Material aNd Methods}

Since the size of our series was restricted from the start by the amount of drug at our disposal, we have limited ourselves to the longest and worst-risk cases from the operating list of a 1000-bed teaching hospital. We were particularly interested in cases where the nature of the operation or the subjects' preoperative condition suggested a difficult recovery. Twenty-six such patients were anaes-

\footnotetext{
* From the Anaesthesia Department of Notre-Dame Hospital, Montreal, Quebec.

$\nmid D r$. Telmosse is Assistant Surgeon at Notre-Dame Hospital.

†Dr. Trop's present address is the Montreal Children's Hospital.
} 
thetized. The anaesthesia time of 20 was longer than three hours. The mean anaesthetic time/dose curve was constructed from the charts of this latter group.

All patients were premedicated with $5 \mathrm{mg}$. (rarely with $10 \mathrm{mg}$.) $\mathrm{R}-4749$ and $0.4 \mathrm{mg}$. atropine subcutaneously one hour before the start of anaesthesia. The anaesthetic mixture contained $2.5 \mathrm{mg}$. R-4749 and $50 \mu \mathrm{g}$. R-4263 per ml., mixed just before the start of anaesthesia. "The patients received $3+5 \mathrm{ml}$. of this " $50: 1$ " mixture intravenously for induction (occasionally more, in one case less) and as soon as marked drowsiness set in, $5 \mathrm{~L}$. nitrous oxide $+2 \mathrm{~L}$. oxygen per minute with assisted respirations by mask were added. About 90 seconds later intubation was carried out with the aid of $50 \mathrm{mg}$. suxamethonium, and the-patient was attached to a mechanical ventilator which provided assisted or controlled respirations at a level not below the patient's predicted ventilation from the Radford nomogram. Once the connections were set up, the anaesthetic gas-flow was reduced to $2 \mathrm{~L}$. nitrous oxide and $1 \mathrm{~L}$. oxygen per minute, and this was kept constant throughout the procedure. The depth of anaesthesia was judged insufficient if the patient stirred, or if his blood-pressure or pulse-rate lrose-this was then corrected with increments of the mixture given intravenously. Experience soon taught us to disregard the fact that some patients opened their eyes when their name was called and even responded by head- or eye-movements to simple questions. Such behaviour was rare when nitrous oxide was employed but it became the rule when this gas was turned off. Muscle relaxant ( $d$-tubocurare) was administered whenever it was deemed necessary to facilitate surgical exposure, that is to say, only some time after artificial respiration had been established. The usual dose was 3-6 mg., never more than $9 \mathrm{mg}$., repeated as required. At no time were our patients curarised in the sense that their muscles would not respond to stimulation through their nerves-we could ascertain this fact every time a major nerve. was exposed and stimulated accidentally during surgery.

Towards the end of surgery the nitrous oxide was turned off and by the time the bandages were applied, all patients responded to their name and had an adequate tidal exchange. A single dose of curare antidote (edrophonium) was administered to one patient in this series. In spite of their alertness the patients did not seem to mind their endotracheal tube: they were therefore transferred with the tube in place to the recovery room and there attached to an assistorventilator for periods ranging up to three hours. Extubation was performed when the patients indicated that the endotracheal tube had become uncomfortable. $\mathrm{CO}_{2}$-output and end-tidal $\mathrm{CO}_{2}$-levels were monitored in most patients during anaesthesia and, in some, during postanaesthetic respiratory assistance-these data were within the normal range in every instance and are not reported here.

\section{Results}

Table I shows our patient material, the interventöons performed, their outcome, muscle relaxant requirements, and related data.

Individual anaesthetic time/dose curves were constructed for each patient

${ }^{*} \mathrm{R}-4749^{\circ}$ (droperidol) and R-4263 (fentanyl) are available for investigational use in a 501 mixture knowñ as Innovan from McNeil Laboratories (Canada) Ltd., 11 Green Belt Drive, Don Mills, Ont., or McNell Laboratories, Inc., Fort Washington, Pa., U.S.A. 


\begin{tabular}{|c|c|c|c|c|}
\hline Age & Sex & Risk & Diagnosis & Intervention \\
\hline 55 & $\mathrm{~F}$ & 2 & $\begin{array}{l}\text { Coronary insuff., bone marrow disease, lung } \\
\text { tumour }\end{array}$ & Pneumonectomy \\
\hline 63 & $M$ & $3+$ & Coronary insuff., alcoholic cirrhosis & Portocaval shunt \\
\hline 36 & M & 1 & Mitral stenosis Gr. 1 & Comissurotomy \\
\hline 19 & M & 4 & Ascites, subcoma, postnecrotic crrthosis & Portocaval shunt \\
\hline 54 & M & 2 & Wasting, radiotherapy & Pneumonectoniy \\
\hline 43 & $\mathrm{~F}$ & 3 & $\begin{array}{l}\text { Advanced renal disease, adrenal insuff., ca. } \\
\text { cervix }\end{array}$ & Wertheim \\
\hline 50 & $\mathrm{M}$ & $3+$ & $\begin{array}{l}\text { Mitral Gr. 3, emboll. cirrhosis, shock after } \\
\text { earlier anaesthetic }\end{array}$ & Commisurrotomy \\
\hline 65 & $\mathrm{~F}$ & 3 & $\begin{array}{l}\text { Hypertensive, on reserpine, coronary, lung } \\
\text { tumour?? }\end{array}$ & Lobectomy \\
\hline $15^{\circ}$ & $F$ & 1 & Patent ductus & Ligation \\
\hline 51 & M & 2 & Marked hypertension & Explor., renal a. \\
\hline 22 & $\mathrm{~F}$ & 2 & Mitral stenosis, Gr. 2 & Commisurrotomy \\
\hline 45 & $\mathrm{M}$ & 1 & Duodenal ulcer & Subtotal gastrectomy \\
\hline 63 & $\mathrm{~F}$ & 4 & $\begin{array}{l}\text { Hb } 6 \text { gms., asthma, coronary, undetermaned } \\
\text { GI-bleeding }\end{array}$ & Gastrectomy \\
\hline 45 & $\mathbf{M}$ & 4 & $\begin{array}{l}\text { Mitral stenosis Gr. } 4 \text {, multiple emboli, ortho- } \\
\text { pnoea, anticoagulänts }\end{array}$ & Commisurrotomy \\
\hline 54 & M & 2 & Obesity, 75 cigarettes daily & Diaphr, hernia repair \\
\hline 42 & $\mathrm{~F}$ & 1 & Low back instability & Spinal fusion \\
\hline 55 & $\mathbf{M}$ & $2+$ & Ascites, dyspnoeae, alcoholic cirrhosis & Portocaval shunt \\
\hline 43 & $\mathrm{~F}$ & 2 & Bronchiectasis & Pneumonectomy \\
\hline 58 & $\mathrm{~F}$ & $2+$ & Pericarditis, coronary, peptic ulcer & Pericardectomy \\
\hline 32 & $\mathrm{~F}$ & 1 & Goitre & Subtotal thyroidect. \\
\hline
\end{tabular}

from the amount of drug administered and the timing of each increment. In order to be comparable, all doses have been expressed in $\mathrm{mg}$. per square metre body surface. The 20 curves and the best-fitting mean time/dose curve computed from them are shown in Figure 1.

Comparison of the mean time/dose curve of the neuroleptic mixture with similar data obtained previously for other anaesthetics ${ }^{1}$ is presented in Table II.

\section{Comment}

A series of such limited size will give information only about what the drug can do. Data about what the drug cannot do or what harmful side-effects it may have will be forthcoming only years later, when series of the order of 10,000 cases can be reviewed. Nevertheless our findings may be of interest because of the special nature of the patient material and also because there have been to date very few reports in the literature about the action of these newest members of the neuroleptic group. The principle of "potentiated" or "balanced" anaesthesia is currently out of favour in America. ${ }^{5}$ This is explained in part by the disillusion 
Lasting Longer than Three Hours

\begin{tabular}{|c|c|c|c|c|c|c|}
\hline \multicolumn{2}{|c|}{$d$-Tubocurare } & \multirow[b]{2}{*}{$\begin{array}{c}\text { Awake, } \\
\text { min. }\end{array}$} & \multirow{2}{*}{$\begin{array}{l}\text { Anaes. } \\
\text { time, } \\
\text { min. }\end{array}$} & \multirow{2}{*}{$\begin{array}{l}\text { Assisted } \\
\text { resp., } \\
\text { min., }\end{array}$} & \multirow[b]{2}{*}{$\begin{array}{l}\text { blood, } \\
\text { units }\end{array}$} & \multirow[b]{2}{*}{ Remarks } \\
\hline mg. & $\begin{array}{c}\text { per } \\
\text { "m.t. }\end{array}$ & & & & & \\
\hline- & $\rightarrow$ & In O.R. & 310 & - & 1 & $\begin{array}{l}\text { Scant urine ovetnight, good } \\
\text { recovery }\end{array}$ \\
\hline 18 & 22 & In O.R. & 410 & 60 & 3 & $\begin{array}{l}\text { bant urine, excellent immediate re- } \\
\text { covery, +4th day in coma, pulm. } \\
\text { oedemd. }\end{array}$ \\
\hline- & - & $\ln$ O.R. & 205 & 50 & 2 & Fair urine, good recovery \\
\hline 48 & 44 & $0+10$ & 405 & 60 & 6 & $\begin{array}{l}\text { Excellent immediate recovery, }+6 \text { th } \\
\text { week of intratable hepatic failure }\end{array}$ \\
\hline 36 & 54 & In O.R. & 285 & $\cdots-$ & 2 & Good recovery \\
\hline 36 & 66 & In O.R. & 240 & 20 & - & Scant ụrine, excellent recovery \\
\hline- & - & In O.R. & 260 & - & 2 & Urine with mannitol only, excellent \\
\hline 27 & 33 & In O.R. & 400 & 110 & 5 & Urinated well, фxcellent recovery \\
\hline 18 & 60 & $0+20$ & 210 & 165 & 2 & Uneventful recovery. \\
\hline 21 & 4 & In O.R. & 200 & 120 & - & $\begin{array}{l}\text { Uneventful recovery; scant urine, re- } \\
\text { quires much sedation postop. }\end{array}$ \\
\hline 12 & 76 & In O.R. & 180 & - & 1 & Uneventful \\
\hline 33 & 31 & $0+5$ & 385 & 120 & 27 & UneventfuI \\
\hline - & - & $0+30$ & 400 & 130 & 3 & $\begin{array}{l}\text { Good immediate recovery, }+5 \text { th day } \\
\text { of recurrent bleeding }\end{array}$ \\
\hline - & - & In O.R. & 280 & $\ldots$ & 2 & $\begin{array}{l}\text { Tracheotomy in O.R., on respirator } \\
\text { for several days postop., excellent } \\
\text { recovery, scant urine for } 36 \mathrm{hr} \text {. }\end{array}$ \\
\hline 18 & 43 & In O.R. & 255 & - & -0 & Uneventful recovery \\
\hline- & & & 910 & 30 & 1 & $\begin{array}{l}\text { "Best recovery" from } 3 \text { recent major } \\
\text { anaesthesias }\end{array}$ \\
\hline 36 & 46 & $\ln O . R$. & 360 & - & 3 & No postanaesthetic complications \\
\hline 6 & 19 & $0+5$ & 200 & 20 & 2 & Excellent recovery. \\
\hline 6 & 13 & $0+10$ & 255 & 125 & - & $\begin{array}{l}\text { No postanaesthetic complications, } \\
\text { scant urine }\end{array}$ \\
\hline - & - & $\ln$ O.R. & 185 & 65 & - & Uneventful recovery \\
\hline
\end{tabular}

that set in when the extravagant claims of the inventors of various systems and mixtures failed to materialize, and in part by the important advances in inhalation anaesthetics that have occurred over the past few years. Still, the actual difference between the techniques employed by "garbage anaesthetists" and by "one-agentmen" is less than one might conclude from the literature. We would classify the technique we have outlined above as a variant of other existing methods for the supplementation of nitrous oxide anaesthesia. This principle is sound because nitrous oxide is the longest known and least harmful general anaesthetic at our disposal. Its only fault is lack of potency.

We have been convinced even by this small series that nitrous oxide anaesthesia can be supplemented advantageously with the neuroleptic mixture. The patients fall asleep quickly and smoothly, they tolerate their endotracheal tubes well, they can undergo very extensive surgery without haemodynamic upsets, and they give timely warning of their lightening anaesthesia. In spite of extensive abdominal procedures on poor-risk patients in our series we have not yet encountered nausea or vomiting among them. To this extent the mixture appears equal to the best nitrous oxide supplements at our disposal today. On 


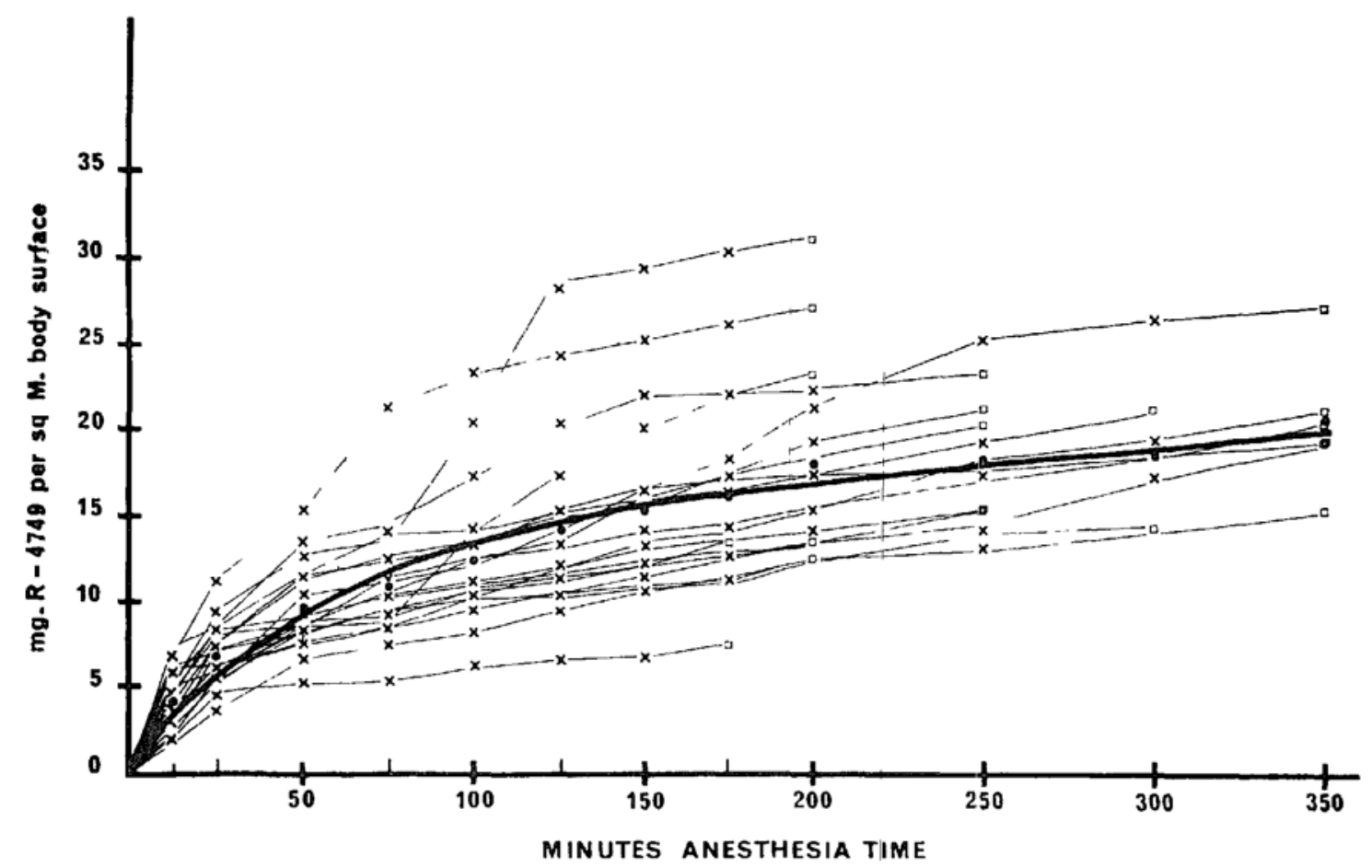

FIGURE 1. Individual and mean anaesthetic time/dose curves of 20 cases. Solid circles indicate the observed mean values at the given times, and the heavy line follows the bestfitting curve computed from the mean values.

TABLE II

Comparison of Time/Dose Curve Constants with Various Intravenous Anaesthetics $Y=A t+B\left(1-e^{-k t}\right)$

\begin{tabular}{|c|c|c|c|c|c|c|}
\hline Drugs & $n$ & $\begin{array}{l}k \\
\text { min. }\end{array}$ & $\begin{array}{c}A, \\
\mathrm{mg} . / \mathrm{m} \cdot{ }^{2} \text {-min. }\end{array}$ & $\begin{array}{c}B, \\
\mathrm{mg} . / \mathrm{mm} .^{2}\end{array}$ & $\begin{array}{l}B / A \text {, } \\
\text { min. }\end{array}$ & $\begin{array}{c}\text { Variability } \\
\text { accounted, } \\
\%_{0}\end{array}$ \\
\hline $\begin{array}{l}\text { Thiopental } \\
\text { Meperidine } \\
\text { Oxymorphone } \\
\text { Thiopental-oxymorphone }\end{array}$ & $\begin{array}{r}104 \\
23 \\
29\end{array}$ & $\begin{array}{ll}0.073 \\
0 & 065 \\
0 & 065\end{array}$ & $\begin{array}{ll}1 & 75 \\
2 & \mathbf{4 4} \times 10^{-1} \\
3 & 56 \times 10^{-3}\end{array}$ & $\begin{array}{ll}2 & 98 \times 10^{2} \\
5 & 53 \times 10^{-1} \\
6 & 63 \times 10^{-1}\end{array}$ & $\begin{array}{l}170 \\
227 \\
184\end{array}$ & $\begin{array}{ll}99 & 4 \\
98 & 5 \\
99 & 4\end{array}$ \\
\hline $\begin{array}{l}\text { mixture } \\
50: 1 \text { neurolept. mixture }\end{array}$ & $\begin{array}{l}44 \\
20\end{array}$ & $\begin{array}{ll}0 & 095 \\
0 & 020\end{array}$ & $\begin{array}{ll}1 & 29 \\
2 & 01 \times 10^{-2}\end{array}$ & $\begin{array}{l}125 \times 10^{2} \\
131 \times 10^{2}\end{array}$ & $\begin{array}{r}97 \\
657\end{array}$ & $\begin{array}{ll}96 & 0 \\
89 & 8\end{array}$ \\
\hline
\end{tabular}

the debit side we noted that intestinal motility is much less than we have become used to with oxymorphone and there is also a very definite lowering of urine output. The latter has been transitory in all our cases but did not respond much to treatment during the anaesthesia itself. Since we did not observe any other changes that would point to deficient renal perfusion, we feel that antidiuresis is the most reasonable explanation. Rigidity of the respiratory muscles during spontaneous ventilation has been reported elsewhere following the use of the drug mixture ${ }^{6}-$ on this we cannot comment since all our subjects were ventilated artificially. Alarming bradycardia or extrapyramidal symptoms that have been described with earlier neuroleptic mixtures ${ }^{3}$ did not occur with our pafients.

Computation of the mean time/dose curve reveals that the best-fitting curve to the observed values has the equation

$$
Y=0.020 t+13.14\left(1-e^{-020 t}\right) \text {. }
$$


This equation will account for 90 per cent of the observed variability, thus confirming that drug requirements with the neuroleptic mixture are subject to the same limiting factor that has been established previously for other anaesthetics. ${ }^{1}$ The low value of $k$ and the $B / A$ ratio of 657 minutes indicates that compared with other anaesthetics (Table II) this mixture, or one of its components, is distributed and inactivated much more slowly. Since experience shows that during this period of inactivation the patients are in possession of their $\mid$ protective reflexes and even of their higher intellectual capacities, the slow inactivation need not be considered as a disadvantage and it might even be put to good use in certain instances.

Peculiar to the neuroleptic mixture is the state of consciousness of the subjects during surgery and their tolerance of the endotracheal tube during induction as well as after surgery. We have mentioned previously that patients responded to their name in the middle of the operation. During postanaesthetic rounds they were questioned, first indirectly and then directly, about their recollections in the operating room and the recovery room. The majority were ampesic for the entire period of ventilatory assistance; six patients who recalled it, did not find it unpleasant. Two patients recalled hearing their name during surgery but they were not aware of pain either. It might be argued that this characteristic of the drugs serves only to impress surgeons or visiting anaesthetists, but we feel that there are patients and procedures where it would be important to avoid cortical disorganization as far as possible. There are for example, geriatric patients in whom the unconsciousness of anaesthesia is sometimes followed by a deterioration of their mental status. In neurosurgical patients or in subjects with advanced liver disease unconsciousness due to anaesthesia might obscure the development of complications or compound the underlying disease.

It should be emphasized that respiratory assistance to our patients in the immediate postanaesthetic period had nothing to do with the depression of their respiratory centre(s). All patients furnished evidence before leaving the operating table that they were capable of producing an adequate tidal exchange on their own, overcoming the resistance of an endotracheal tube and of the anaesthetic machine. We consider that their artificial respiration in the recovery room served to their advantage by reducing muscular effort and the need for additional analgesic medication. For the time being we were unable to measure it in any exact sense, but we have the very definite impression that the patients benefit from postanaesthetic artificial ventilation. Once they settle down, they lapse into light sleep from which they can be easily roused by voice or touch. They are oriented, they show by signs or by writing short notes that they want their positions changed or that they are in pain. To our minds, the postanaesthetic characteristics constitute one of the main advantages of this drug mixture.

In this study we have intentionally selected patients who represented far worse than the average risk by nature of their physical status, the type and duration of proposed surgery, or other complicating factors. Our results justify the opinion that the neuroleptic mixture is a useful supplement of nitrous oxide anaesthesia. It might be particularly useful in geriatric surgery, in prolonged anaesthetics, and in cases where postanaesthetic respiratory assistance appears beneficial. 


\section{Summary}

1. Nitrous oxide anaesthesia was supplemented with a 50:1 mixture of $R-4749$ and $\mathrm{R}-4263$ as well as muscle relaxants in a selected group of poor-risk patients scheduled for prolonged surgery. The mean anaesthetic time/dose curve for these subjects has been calculated.

2. The results indicate that the neuroleptic anaesthesia requirements are subject to the same limiting factors as other intravenous anaesthetics and that the drugs are relatively slowly distributed and metabolized in the body.

3. Attention is called to the fact, among other peculiarities, that patients in this series retained more of their consciousness than with other intravenous anaesthetics and that they tolerated their endotracheal tubes for substantial periods after awakening. These characteristics suggest special indications for the anaesthetic in geriatric surgery, in patients who are marginally conscious preoperatively, and in those who might benefit from ventilatory assistance in the immediate postanaesthetic period.

\section{REFERENCES}

1. Kè̀ru-SzÀntò, M. Anesthetic Time/Dose Curves II. The' Limiting Factor in the Utilization of Intravenous Anesthetics during Surgical Operations.' Clin. Pharm. Therap. 2: 45 (i961).

2. - - Drug-Consumption during Thiopentone-Nitrous Oxide-Relaxant Anaesthesia: The Preparation and Interpretation of Time/Dose Curves. Brit. J. Anaesth. 32:-415 (1960).

3. DeCastro, J. \& Mundeleer, P. Dehydrobenzperidol et Phentanyl: Deux anesthesiques nouveaux qui apportent de nouvelles possibilitès à la neuroleptanalgesie. Symposium, Vienna, 1962, p. 1.

4. -- Anesthésie sans barbituriques: La Neuroleptanalgésie. Anesth. \& Analg. 16: 1022 (1959).

5. MARx, G. F. Comment in Survey of Anesthesiology 6:516 (1962).

6. Holderness, M. D.; Chase, P. E.; \& Dripps, R. D. Use of a Narcotic Analgesic and Butyrophenone with Nitrous Oxide for General Anesthesia. Anesthesiology 24. 336 (1963). 